\title{
European Journal of Educational Research
}

Volume 11, Issue 2, 653 - 661.

ISSN: 2165-8714

https://www.eu-jer.com/

\section{Implementing Synchronous Online Flipped Learning for Pre-service Teachers During COVID-19}

\author{
Yong-Jik Lee $(D)$ \\ Woosuk University, SOUTH KOREA
}

\author{
Robert Davis* ${ }^{*}$ \\ Hankuk University of Foreign Studies, \\ SOUTH KOREA
}

\author{
Yue Li (iD) \\ Woosuk University, SOUTH KOREA
}

Received: November 9, $2021 \cdot$ Revised: December 24, $2021 \cdot$ Accepted: January 6, 2022

\begin{abstract}
Most research has examined flipped learning within the context of face-to-face (F2F) instruction. However, previous research has not effectively explored the possibility of how online synchronous flipped learning influences pre-service teachers (PSTs) in teacher education programs during Coronavirus disease (COVID-19). Recognizing the gap in the literature, this paper explored three aspects of online synchronous flipped learning by understanding 1) PSTs' learner engagement, 2) self-directed learning, and 3) learner satisfaction in a Korean university. The data was collected from Korean PST's interviews, reflection notes, and course evaluations. The thematic analysis was used to analyze qualitative data sources. The study findings showed that PSTs favored a synchronous online FL because it encouraged them to engage in various collaborative activities through Zoom breakout sessions. Also, pre-class materials from online FL can positively enhance the PSTs' self-directed learning process. Based on these findings, this study provides suggestions on how to effectively implement online synchronous flipped learning in teacher education programs.
\end{abstract}

Keywords: COVID-19, flipped learning, higher education, pre-service teachers, synchronous and asynchronous online learning.

To cite this article: Lee, Y., Davis, R., \& Li, Y. (2022). Implementing synchronous online flipped learning for pre-service teachers during COVID-19. European Journal of Educational Research, 11(2), 653-661. https://doi.org/10.12973/eu-jer.11.2.653

\section{Introduction}

As Coronavirus disease (COVID-19) spread globally in early 2020, the traditional face-to-face (F2F) education model had to be modified at every level. Educators faced crucial challenges in transitioning course formats from F2F to online learning (Ferdig et al., 2020; Flores \& Gago, 2020). For higher education, the pandemic forced teacher educators to rapidly readjust the instructional model for pre-service teachers (Baran \& AlZoubi, 2020) because the Ministry of Education in Korea announced that all university courses would transition online (Chang et al., 2020; Kim et al., 2020). Guided by the Korean MOE's new policies, Korean universities were forced to adopt online education, which meant teacher educators in Korea had to conduct synchronous or asynchronous online courses (Chang et al., 2020; Kim et al., 2020). Synchronous courses require instructors to teach classes in real-time with students via video conferencing software; while asynchronous classes allow instructors to post teaching materials, such as lecture videos, on a Learning Management System (LMS) so that PSTs are able to complete materials in a designated timeline.

Flipped Learning (FL) is defined as "a pedagogical approach in which direct instruction moves from the group learning space to the individual learning space, and the resulting group space is transformed into a dynamic, interactive learning environment where the educator guides students as they apply concepts and engage creatively in the subject matter" (Flipped Learning Network, 2014). In the FL model, the traditional direct teaching method is repositioned as an out-ofclass activity so that in-class time can focus on problem-solving or project-based learning. In this environment, the instructor's role is similar to that of a learning coach or facilitator (Karabulut-Ilgu et al., 2018). Thus, FL could provide more hands-on and student-driven activities during the in-class time. The advantages of an FL include increased student motivation, self-pacing learning, mastery learning, increased collaboration, and instant feedback through assessment (Gianoni-Capenakas et al., 2019; Turan \& Akdag-Cimen, 2020). Many universities have embraced the FL model because it provides increased peer interaction and deeper engagement with the material.

Previous studies have documented that the asynchronous teaching approach in the FL frees up in-class time to receive meaningful learning experiences through higher-order thinking activities (Uzunboylu \& Karagozlu, 2015; Zhang et al.,

\footnotetext{
* Corresponding author:

Robert Davis, Hankuk University of Foreign Studies, Seoul, South Korea. $₫$ red1020@gmail.com
} 
2014). Similarly, previous research suggests that FL allows university faculty members to provide more individualized and customized instruction for all students (Estes et al., 2014; Hao, 2016). However, previous research has mainly focused on the F2F context, which is disconnected from the online context. It is not fully understood how online synchronous flipped learning influences learning engagement, self-directed learning, and satisfaction with PSTs. To explore the gap in the pre-existing literature, this research aims to understand PSTs' engagement, self-directed learning, and satisfaction with FL during COVID-19.

\section{Literature Review}

\section{FL on Learner Engagement}

Previous studies have shown that learner engagement is a core element of delivering quality higher education. Learner engagement is also related to academic success, favorable educational outcomes, and student satisfaction (Appleton et al., 2008). Several studies have documented the positive relationship between the two factors (Doo, 2022; Fisher et al., 2018; McLaughlin et al., 2016; Norazmi et al., 2017). For instance, Fisher et al. (2018) argued that flipped learning could positively influence learner engagement, performance, and satisfaction. Study results showed that the learner engagement stimulated by FL could make students satisfied in terms of their perceptions of learning performance. Similarly, McLaughlin et al. (2016) compared student engagement with FL. The results indicated that students who attended FL classes performed significantly better on examination than students who did not attend FL classes. Norazmi et al. (2017) examined students' engagement in FL through a self-developed questionnaire. Study findings suggest that the FL could promote students' writing process for emotion (3.88), cognition (3.95), and behavior (3.96). The authors recommended FL be implemented in all areas of language learning by providing practical guidelines for instructors and learners to maximize the flipped classroom experience. Doo (2022) examined various variables influencing learners' perceptions, perceived usefulness, and learning engagement. The results showed that the benefits of FL were facilitating learners' understanding of lectures, providing flexible learning time, and creating individual learning. Overall, research has shown that FL positively influences learning engagement for university students (Doo, 2022; Fisher et al., 2018; McLaughlin et al., 2016; Norazmi et al., 2017).

\section{FL on Self-Directed Learning}

Regarding the impact of FL on students' self-directed learning, previous studies have documented the relationship between the two factors (Ceylaner \& Karakus, 2018; Chung, 2018; Kim et al., 2014; Zainuddin \& Attaran, 2016; Zhang et al., 2014). Specifically, Ceylaner and Karakus investigated how the FL could affect students' self-directed learning and attitudes. Results indicated that there was a significant difference between the experimental (FL intervention) and control group (no intervention) regarding self-directed learning readiness and attitudes towards the English course. In another study, Chung explored the effects of FL on self-directed learning and class satisfaction for university students. The results suggest that the FL has a significant impact on students' self-directed learning. More specifically, the results showed significant differences in university students' goal setting, self-directed learning and problem-solving excellence, class methods, and content understanding.

Zainuddin and Attaran (2016) investigated university students to identify the impact of the LMS in enhancing their selfdirected learning ability through FL courses. Study findings showed that the FL could enable students to foster their selfdirected learning pace and with the pre-recorded instructors' video lectures. In another study, Kim et al. (2014) explored the effects of FL activities on learners' self-directed learning and collaborative learning. The FL was found to have improved self-directed learning ability more than the traditional method. In addition, collaborative learning was more improved with a significance in FL learning methods than the traditional method group. These studies have shown that FL can boost university students' self-directed learning via pre-recorded lectures and materials before the designated class time (Ceylaner \& Karakus, 2018; Chung, 2018; Kim et al., 2014; Zainuddin \& Attaran, 2016; Zhang et al., 2014).

\section{FL on Learner Satisfaction}

Learners' satisfaction is an essential element of assessing the effectiveness of teaching and learning (O'Flaherty \& Phillips, 2015). Students who perceive satisfaction with their academic performance can experience a sense of academic achievement (O'Flaherty \& Phillips, 2015). Regarding the relationship between FL and students' satisfaction, several studies have shown that FL has a positive impact on students' satisfaction towards FL (Kim, 2018; Martínez-Jiménez \& Ruiz-Jiménez, 2020; Samaila et al., 2021).

For instance, Lin and Chen (2016) concluded that flipped learning positively affects learning satisfaction and learning effectiveness. Similarly, Martínez-Jiménez and Ruiz-Jiménez (2020) explored flipped classrooms in a Spanish university. Results show that students are very satisfied with the FL experience because they consider their learning process effective with FL modules. Furthermore, the authors argued that students' academic results could improve with flipped courses, compared with traditional lectures.

Kim (2018) explored students' reflections on flipped learning in a Korean university. The author examined relationships among learning styles, personality traits, and satisfaction from FL classes. Study results indicated that students in FL 
showed better content understanding, convenience learning time and pace, and enhanced interactions among classmates. However, it was also reported that heavy workloads, more time preparation, and the lack of familiarity and motivation were mentioned as downsides of FL. In another study, Li et al. (2015) re-designed an undergraduate course by integrating MOOC content and FL to examine its effectiveness in students' experience and perceptions. Study results indicate that students were generally satisfied with the FL course, including instructor response time, e-learning course flexibility, perceived usefulness, perceived ease of use, and perceived e-learner satisfaction. To sum up, these studies have shown that FL can positively impact university students' satisfaction level (Li et al., 2015; Lin \& Chen, 2016; Samaila et al., 2021).

This study aimed to understand three aspects of understanding online FL by examining Korean pre-service teachers' 1) learner engagement, 2) self-directed learning, and 3) satisfaction during COVID-19. Therefore, three research questions are proposed.

1. How does online flipped learning affect pre-service teachers' learner engagement?

2. How does online flipped learning affect pre-service teachers' self-directed learning?

3. How does online flipped learning affect pre-service teachers' satisfaction with the technology integration course?

\section{Methodology}

\section{Research Context}

The current study was conducted in a teacher education program at a private university located in the southwest region of South Korea. The university has a teacher education program that shares courses with various educational departments. Due to COVID-19, the university decided to conduct online synchronous classes via Zoom during the scheduled class times. Among various teacher education courses, Teaching Methods and Educational Technology, was selected because it focused on teaching methodology, prominent theories in online education, and integrating an educational technology component. Traditionally, the class during previous semesters had been more teacher-centered with lecture-based classes without an online learning component, such as using the LMS.

However, due to the 2020 pandemic, the instructor was required to change the course structure to be more studentcentered in an online learning environment. Before attending the Zoom synchronous class time, PSTs were required to watch the instructor's pre-recorded lectures and supplementary YouTube videos based on the chapter content. The preclass videos were connected to an LMS that allowed the instructor to monitor and track each participant's completion with the materials. The synchronous Zoom also allowed the instructor to incorporate various team-based collaborative activities, such as group discussion, making lesson plans for technology integration, online micro-teaching, giving and receiving feedback sessions in Zoom breakout rooms, and crafting Google classrooms. After a Zoom synchronous class, PSTs were required to submit reflections based on the covered contents each week. This course was a mandatory course for PSTs to receive a teaching certificate upon graduation. The course was divided into four different classes in 2020 Spring and 2020 Fall, with each class consisting of 18-24 PSTs.

\section{Study Participants}

There was a total of 140 Korean undergraduate PSTs during the 2020 academic year (2020 spring and 2020 fall). The course was open to all teacher education majors. Hence, the course included several different majors, such as special education, early childhood education, Korean language teaching, English language teaching, math education, and physical education. A total of 4 participants voluntarily agreed to in-depth interviews after completing flipped learning experiences. See Table 1 for a brief description of the interview participants.

Table 1. Interview Participants

\begin{tabular}{lllcc}
\hline Interview Participants & $\begin{array}{l}\text { Gender/ } \\
\text { Age }\end{array}$ & Major & $\begin{array}{r}\text { Previous } \\
\text { Micro-teaching experience }\end{array}$ & $\begin{array}{c}\text { Previous Field } \\
\text { Experience }\end{array}$ \\
\hline Participant 1 & Female/22 & Special Education & 0 & X \\
Participant 2 & Female/23 & Special Education & X & X \\
Participant 3 & Male/24 & Korean Language Teaching & X & 0 \\
Participant 4 & Male/26 & Korean Language Teaching & 0 & 0 \\
\hline
\end{tabular}

\section{Data Collection and Analysis}

The data was collected in the 2020 academic year, including the 2020 spring semester (from April to July) and the 2020 Fall semester (September to December). This study used three data sources: 1) PSTs' course evaluations after each semester $(n=140), 2)$ PSTs' reflections after each semester $(n=70)$, and 3) PSTs' individual interviews after 2020 fall semester $(n=4)$. 
Informed consent forms were collected before each semester. A research assistant conducted a 20-30-minute interview in Korean with the interview participants. All interviews were recorded through Zoom. PSTs' reflections were collected from the course LMS at the end of the semester. Example questions of reflections included: What was your flipped learning experience? What did you learn about incorporating educational technology in your lesson plan? What were your biggest take-aways from this FL course? Thematic analysis was used to analyze qualitative data sources (Clarke \& Braun, 2018). First, the research team transcribed all data sources. Recordings for interviews were re-listened for accurate interview transcription and saved to Dropbox. Second, the research team created initial codes and sub-codes while organizing all data sources. The third step was theme development, where the research team reread to identify significant broader patterns of meaning or potential themes. Fourth, several themes were combined into small numbers and further reduced to the most frequent categories. Fifth, the research team defined themes for abstraction and data reduction. In the last step, all three data analysis was triangulated to create a final report.

\section{Findings}

The data analysis showed that online FL could positively influence 1) PSTs' learner engagement, 2) self-directed learning, and 3) satisfaction.

\section{Online FL on Learner Engagement}

Firstly, many PSTs wrote reflections during the class that the online FL through zoom breakout sessions helped them actively engage in various group discussions and collaborative activities. PSTs responded that they liked group activities because this interaction encouraged them to reflect on the material that they pre-viewed. Course evaluation data analysis also confirmed this theme. Here is one of the examples from PSTs' reflection notes.

At the beginning of the Zoom synchronous class, we were always participating in the group discussion about what we pre-viewed. While writing our summary of chapters by using a Google document, we collaboratively work together and write down what we had learned. This group discussion activity helped us more engaged in class activities (PST'S reflection, \#23).

The interview data also showed the benefit of online FL on learner engagement through various collaborative activities in the Zoom breakout sessions.

I have never used Google Drive and Google documents previously. But it was a really good tool to engage in-class activities during zoom breakout sessions. For example, when we worked on lesson plans for online micro-teaching, the instructor provided us feedback in real-time. It helped us better design our team's lesson plan (PST's interview, \#4).

However, a few PSTs mentioned the limitation of synchronous online FL. Since the instructor had to rotate the breakout rooms to check each group's class participation, the team member's level of motivation for class activities could be different. This is one of the limitations of online FL from the interview.

For each week, the instructor randomly assigned groups. It was good for us to interact with different people and majors each week, but if the group had students who were less motivated to participate in class activities, the group discussion was not effective as it should be. So, I think it depends on who you had in that group (PST's interview, \#2).

Although it was found that FL had few limitations, PSTs' responses were mostly positive, and PSTs mentioned that online FL actively encouraged them to participate more during the Zoom synchronous class time.

\section{Online FL on Self-Directed Learning}

Second, many PSTs wrote that the pre-class materials of online FL could promote their self-regulated learning before attending synchronous Zoom class. PSTs liked pre-loading materials because they could cover materials in advance in their convenient timeline. Also, the online FL course structure helped them become more self-directed learners. Many PSTs recognized that online FL helped them promote their self-directed learning. In course evaluations, PSTs mentioned that this FL course were different from other lecture-based courses and FL experience was interesting and provided them new perspective. Here are some examples from course evaluations.

I like pre-class materials on LMS because I can watch and re-watch those whenever I want. I felt that I am more prepared through self-study before participating in the actual class time (PST's course evaluation, \#10).

In F2F class, when the instructor's speech and explanation are really fast, I am anxious that I may miss something important in the class. But thanks to LMS, I can study myself before class if I do not clear about certain concepts in the textbook chapter (PST's course evaluation, \#78).

A few PSTs showed the burden of pre-loading materials that they had to explore. Korean PSTs are accustomed to receiving teacher-centered direct instruction in their K-12 environment. Thus, a few of PSTs had to adjust to the new learning environment during the pandemic. PSTs mentioned that it was challenging to adjust themselves to become more self-directed learner and active learner at the beginning of the semester. Here is one example from the interview. 
At first, it was challenging for me to work on myself to cover all of these pre-class materials. Once the semester proceeds, I can slowly adjust this online FL format. But it was definitely challenging at the beginning of the semester because I do not have a habit of studying material by myself in advance (PST's interview, \#3).

However, once the semester proceeded with the online FL format, PSTs realized that they became more independent learners and they liked to explore the provided materials before the synchronous Zoom class. This gradual change was found throughout the data analysis.

I feel like I become more independent and self-directed learner thanks to flipped learning. Also, understanding studentscentered classrooms guided by Constructivism is one of the key concepts that I learned from this course. This course makes me prepared to become active learner in the teacher education courses (PST's course evaluation, \#69).

These responses showed that online FL made PSTs more independent learners and fostered their self-directed learning. As a result, PSTs realized that self-directed learning was the key to online FL.

\section{Online FL on Learner Satisfaction}

Third, the data analysis indicated that PSTs generally showed positive satisfaction for online FL after the semester. They mentioned that online FL could help their future teaching plan based on instructional design purposes. PSTs were fully aware of the importance of online education during the pandemic, so they believed that this online FL would be one of the instructional options they could implement when they became in-service teachers. Here are examples from reflections.

We had to do online education anyhow during the pandemic. So, I think that this online FL format is one of the effective ways of achieving this goal. Based on what I had learned from this course, I can also try out my own online FL for my future classrooms (PST's reflection, \#65).

When a similar situation happens like this pandemic, we, as teachers, need to prepare how to do online education. So, this online FL actually provided us some guidelines and sets of tools on how we can do it for future purpose (PST'S reflection, \#72).

The interview data also showed a similar pattern of PSTs' positive satisfaction with online FL, especially on the LMS. PSTs showed a positive attitude towards the established LMS for online FL, although it was short notice because of an unexpected pandemic in early 2020.

We took several online courses so far in 2020. We experienced some good and bad cases from different professors. This class was one of the effective ones. All necessary materials were already posted on the LMS. What I needed to do was to locate and navigate the right source (PST's interview, \#1).

Course evaluations also supported this theme. Many PSTs wrote that this course was one of the best prepared online courses during the 2020 pandemic. PSTs enjoy the FL experience and generally showed positive satisfaction about the online FL experience.

\section{Discussion}

This paper aimed to understand three aspects of online FL by exploring PSTs' 1) learner engagement, 2) self-directed learning, and 3) satisfaction. Data analysis evaluated these aims by using PST's responses, which included course evaluations, reflections, and interviews.

RQ1: How does online flipped learning affect pre-service teachers' learner engagement?

Firstly, PSTs responded that the online FL with Zoom breakout sessions promoted active learning engagement through various group discussions and collaborative team activities. Many PSTs preferred the Zoom breakout sessions in the synchronous online FL because it helped them receive feedback from their peers regarding pre-viewed materials. PSTs also confirmed that the feedback from the instructor in real-time was a valuable learning experience as opposed to the asynchronous course format without feedback or interaction with the course instructor. These findings indicated that synchronous online FL could be more beneficial compared to the asynchronous format without interaction between students and the instructor (Marshall \& Kostka, 2020). Previous studies have confirmed that FL can positively impact learners' engagement (Doo, 2022; Fisher et al., 2018; Lo et al., 2021; Norazmi et al., 2017). This study's findings also matched previous studies that online FL could promote students' active online class participation through various collaborative and team-based activities (Fisher et al., 2018; Lo et al., 2021; Norazmi et al., 2017). Thus, it was concluded that online FL could also positively influence PSTs' learning engagement. 
RQ2: How does online flipped learning affect pre-service teachers' self-directed learning?

In terms of online FL on self-directed learning, PSTs responded that pre-class materials promoted their self-regulated learning before attending synchronous Zoom class. PSTs mentioned that they could watch or re-watch assigned materials conveniently, which helped them enhance their self-directed learning. In the 2020 spring semester, many PSTs struggled to adjust to being active and independent learners, but in the 2020 fall semester, they were familiar with online learning and realized how they could learn the content effectively. They liked the combined use of the LMS and Google Drive with online FL because they believed that it was a helpful educational tool. Previous studies have also confirmed that FL can encourage students to explore materials in advance so that they can be more self-directed learners by using the LMS (Balci et al., 2021; Ceylaner \& Karakus, 2018; Kim \& Choi, 2018). This study also provided evidence that pre-loaded materials, including pre-recorded online lectures, encourage PSTs to become more independent and self-directed learners through online FL. Also, these materials made PSTs more prepared before engaging in Zoom synchronous class. These findings were closely matched with previous studies' results (Balci et al., 2021; Ceylaner \& Karakus, 2018; Kim \& Choi, 2018).

\section{RQ3: How does online flipped learning affect pre-service teachers' satisfaction with the technology integration course?}

The PSTs showed positive satisfaction towards online FL because they recognized the importance of online education during the pandemic. Also, if they had to implement online education when they became in-service teachers, they were more likely to implement online FL because the class in this study provided them with guidelines, helpful tips, and tools to try out online FL for future purposes. These responses indicated that online FL could help PSTs reflect on what they had learned from course materials. Previous studies have indicated that FL can positively impact students' positive online course satisfaction (Kim, 2018; Samaila et al., 2021; Yilmaz, 2017; Zhai et al., 2017). This study also showed that FL could promote PSTs' online course satisfaction in terms of technology integration because PSTs realized the need to apply the necessary knowledge and skills needed to integrate educational technology for online courses during the COVID-19 pandemic.

\section{Conclusion}

The COVID-19 has required teacher educators to critically examine their approaches to teaching within the context of online learning. Based on study findings, several implications are discussed in terms of the implementation of online FL. Firstly, PSTs in the current study responded that a synchronous Zoom is mandatory for effective online FL. This is because the Zoom synchronous class allowed students to interact with the instructor and peers so that students do not feel left out. PSTs also compared their course experiences between synchronous and asynchronous and concluded that they definitely preferred synchronous courses. These findings indicated that although teacher educators had to conduct online education, the synchronous class time should be established as similar to F2F because PSTs feel more connected and receive more benefits from their learning process. Although these digital natives quickly adjusted to the online environment, they still want to have human interaction even in the online space. Thus, the asynchronous courses without human interaction may not be as effective in the pandemic situation (Lo et al., 2021; Marshall \& Kostka, 2020).

Secondly, study findings also showed that the faculty's readiness for online FL could positively impact the level of PSTs' course satisfaction regarding online education. In the early outbreak of pandemic in 2020 February, the research team predicted the necessity of conveying online education and intensively created an online FL immediately. This pre-active preparation helped the research team to effectively implement online FL for PSTs in the 2020 academic year, while some teacher educators were still struggling to find a way of effective online education. This preparation indicated that the university around the world should provide professional development for faculty on how to effectively convey the blended learning format in case of a similar future pandemic situation (Flores \& Gago, 2020). Without the ability of instructional designers, it will be continuously challenging for teacher educators to effectively construct blended learning through the online FL format (Ferdig et al., 2020).

Thirdly, our study showed that PSTs had different levels of self-directed learning based on their prior online learning experiences. Some students struggled because they were accustomed to lecture-based courses that heavily focused on teacher-directed instruction in a standardized testing environment during K-12 education. Thus, it was difficult for PSTs to quickly adjust to online education with team-based activities at the beginning of the 2020 Spring semester. However, in the 2020 Fall semester, PSTs were more prepared for the Zoom synchronous session, which indicated that they were ready to participate in group activities. In terms of pre-course activities, PSTs were willing to spend more time rewatching the materials as the semester went by. Thus, it is necessary for teacher educators to explore how PSTs' previous learning experiences of online education can eventually influence the different levels of PSTs' self-regulated learning.

\section{Recommendations}

Based on study findings, this paper provided several recommendations in terms of how to effectively implement online FL for PSTs during COVID-19. 
It is suggested that future researchers focus on comparing PSTs' synchronous and asynchronous FL learning experiences to gain a better understanding of the various benefits each design has PSTs' academic success and satisfaction. Since there have only been a few studies exploring the differences between synchronous and asynchronous FL experiences for PSTs, it is unknown to what extent learning activities need to be designed or delivered to create a beneficial experience. For example, would tasks aimed at constructing mental models benefit from asynchronous delivery, while synchronous classes are used to help PSTs challenge and reformulate existing models of knowledge? This research area should be further investigated.

\section{Professional development for university faculty}

Various PD opportunities can help future practitioners to better understand how to implement instructional design for online FL. In addition, future researchers need to constantly explore how PD in university institutions can boost the faculty's ability and competency of conducting online FL and how it can eventually influence the PSTs' academic performance and achievement. It is necessary for future studies to explore the relationship between the faculty's PD and students' academic success.

\section{Examining PSTs' previous online experience}

Future research needs to critically examine the relationship between a learner's previous online learning experience and self-directed learning through an online FL format. Understanding if different outcomes are a result of learners' failure to comprehend how to study online is relatively unknown. This knowledge can help educators prepare classes that offer better assistance to those students needing extra support to be successful in the online environment. These learners' diverse backgrounds about prior online learning experience can help future researchers to understand the impact of PSTs' course satisfaction towards online FL. Therefore, future researchers had to design research that considers PSTs' prior online learning experience.

\section{Limitations}

Study findings from this research could contribute to knowledge and practices regarding pre-service teachers' preparation through online FL during COVID-19. However, it should be noted some limitations of this research. First, PSTs in this study were pre-service teachers at one private university in South Korea. Since teacher education programs could be different from university to university worldwide, several findings at the current university may be different from study findings in other teacher education programs. Thus, larger-scale research, including many different teacher education programs with various countries, can provide additional insights related to PSTs' FL experiences during the pandemic. It is also necessary to recognize that PSTs' level of academic achievement and previous online learning experiences of FL was not asked. It could be possible that other questions regarding PSTs' FL experience may show additional findings and suggestions.

\section{Authorship Contribution Statement}

Lee: Conceptualization, design, writing the first draft. Davis: Editing, final approval. Li: Data collection and analysis.

\section{References}

Appleton, J. J., Christenson, S. L., \& Furlong, M. J. (2008). Student engagement with school: Critical conceptual and methodological issues of the construct. Psychology in the Schools, 45(5), 369-386. https://doi.org/10.1002/pits.20303

Balci, T., Temiz, C. N., \& Sivrikaya, A. H. (2021). Transition to distance education in COVID-19 period: Turkish pre-service teachers' e-learning attitudes and readiness levels. Journal of Educational Issues, 7(1), 296-323. https://doi.org/10.5296/jei.v7i1.18508

Baran, E., \& AlZoubi, D. (2020). Human-centered design as a frame for transition to remote teaching during the COVID19 pandemic.Journal of Technology and Teacher Education,28(2), 365-372. https://www.learntechlib.org/p/216077/

Ceylaner, S. G., \& Karakus, F. (2018). Effects of the flipped classroom model on students' self-directed learning readiness and attitudes towards the English course. English Language Teaching, 11(9), 129-143. https://bit.ly/3q8ji9R

Chang, D. G., Park, J. B., Baek, G. H., Kim, H. J., Bosco, A., Hey, H. W. D., \& Lee, C. K. (2020). The impact of COVID-19 pandemic on orthopaedic resident education: A nationwide survey study in South Korea. International Orthopaedics, 44(11), 2203-2210. https://doi.org/10.1007/s00264-020-04714-7

Chung, E. (2018). Flipped learning: The effects of flipped learning on self-directed learning and class satisfaction in a class of college physical therapy students. Journal of The Korean Society of Integrative Medicine, 6(4), 63-73. https://doi.org/10.15268/ksim.2018.6.4.063 [In Korean] 
Çil, O. (2021). An educator's response to COVID-19: Preservice teachers' perspectives on flipped distance education. IAFOR Journal of Education, 9(2), 37-53. https://doi.org/10.22492/ije.9.2.03

Clarke, V., \& Braun, V. (2018). Using thematic analysis in counselling and psychotherapy research: A critical reflection. Counseling and Psychotherapy Research, 18(2), 107-110. https://doi.org/10.1002/capr.12165

Doo, M. Y. (2022). Understanding flipped learners' perceptions, perceived usefulness, registration intention, and learning engagement. Contemporary Educational Technology, 14(1), 1-14. https://doi.org/10.30935/cedtech/11368

Estes, M. D., Ingram, R., \& Liu, J. C. (2014). A review of flipped classroom research, practice, and technologies. International HETL Review, 4(7). https://bit.ly/3HCLQhA

Ferdig, R. E., Baumgartner, E., Hartshorne, R., Kaplan-Rakowski, R., \& Mouza, C. (2020). Teaching, technology, and teacher education during the COVID-19 pandemic: Stories from the field. Association for the Advancement of Computing in Education (AACE).

Fisher, R., Perényi, Á., \& Birdthistle, N. (2018). The positive relationship between flipped and blended learning and student engagement, performance and satisfaction. Active Learning in Higher Education, 22(2), 97-113. https://doi.org/10.1177/1469787418801702

Flipped Learning Network. (2014). The Four Pillars of FLIP. https://flippedlearning.org/definition-of-flipped-learning

Flores, M., \& Gago, M. (2020). Teacher education in times of COVID-19 pandemic in Portugal: national, institutional and pedagogical responses. Journal of Education for Teaching, 46(4), 507-516. https://doi.org/10.1080/02607476.2020.1799709

Gianoni-Capenakas, S., Lagravere, M., Pacheco-Pereira, C., \& Yacyshyn, J. (2019). Effectiveness and perceptions of flipped learning model in dental education: A systematic review.Journal of Dental Education, 83(8), 935-945. https://doi.org/10.21815/IDE.019.109

Hao, Y. (2016). Exploring undergraduates' perspectives and flipped learning readiness in their flipped classrooms. Computers in Human Behavior, 59, 82-92. https://doi.org/10.1016/j.chb.2016.01.032

Karabulut-Ilgu, A., Jaramillo Cherrez, N., \& Jahren, C. T. (2018). A systematic review of research on the flipped learning method in engineering education. British Journal of Educational Technology, 49(3), 398-411. https://doi.org/10.1111/bjet.12548

Kim, J. Y. (2018). A study of students' perspectives on a flipped learning model and associations among personality, learning styles and satisfaction. Innovations in Education and Teaching International, 55(3), 314-324. https://doi.org/10.1080/14703297.2017.1286998

Kim, M., \& Choi, D. (2018). Effects of self-directed learning readiness on academic performance and perceived usefulness for each element of flipped learning. Educational Technology International, 19(1), 123-151. https://papersearch.net/thesis/article.asp?key=3614819

Kim, M. H., Cho, W., Choi, H., \& Hur, J. Y. (2020). Assessing the South Korean model of emergency management during the COVID-19 pandemic. Asian Studies Review, 44(4), 567-578. https://doi.org/10.1080/10357823.2020.1779658

Kim, S. H., Park, N. H., \& Joo, K. H. (2014). Effects of flipped classroom based on smart learning on self-directed and collaborative learning. International Journal of Control and Automation,7(12), 69-80. https://doi.org/10.14257/ijca.2014.7.12.07

Li, Y., Zhang, M., Bonk, C. J., \& Guo, Y. (2015). Integrating MOOC and flipped classroom practice in a traditional undergraduate course: Students' experience and perceptions. International Journal of Emerging Technologies in Learning, 10(6), 1-10. https://doi.org/10.3991/ijet.v10i6.4708

Lo, C. K., Cheung, K. L., Chan, H. R., \& Chau, C. L. E. (2021). Developing flipped learning resources to support secondary school mathematics teaching during the COVID-19 pandemic. Interactive Learning Environments, 29(8), 1-19. https://doi.org/10.1080/10494820.2021.1981397

Lin, P. C., \& Chen, H. M. (2016). The effects of flipped classroom on learning effectiveness: using learning satisfaction as the mediator. World Transactions on Engineering and Technology Education, 14(2), 231-244. https://bit.ly/3taJwu4

Marshall, H. W., \& Kostka, I. (2020). Fostering teaching presence through the synchronous online flipped learning approach. TESL-EJ, 24(2), 1-14. https://eric.ed.gov/?id=E]1268565

Martínez-Jiménez, R., \& Ruiz-Jiménez, M. C. (2020). Improving students' satisfaction and learning performance using flipped classroom. The International Journal of Management Education,18(3), 100422. https://doi.org/10.1016/j.ijme.2020.100422 
McLaughlin, J. E., White, P. J., Khanova, J., \& Yuriev, E. (2016). Flipped classroom implementation: A case report of two higher education institutions in the United States and Australia. Computers in the Schools, 33(1), $24-37$. https://doi.org/10.1080/07380569.2016.1137734

Norazmi, D., Dwee, C. Y., Suzilla, J., \& Nurzarina, A. S. (2017). Exploring student engagement in writing using the flipped classroom approach.Pertanika Journal of Social Science and Humanities, 25(2), 663-674. https://bit.ly/3HRWEZn

O'Flaherty, J., \& Phillips, C. (2015). The use of flipped classrooms in higher education: A scoping review. The Internet and Higher Education, 25, 85-95. https://doi.org/10.1016/j.iheduc.2015.02.002

Samaila, K., Masood, M., \& Chau, K. T. (2021). Using flipped classroom model: Factors influencing students' satisfaction. European Journal of Interactive Multimedia and Education, 2(2), 1-9. https://doi.org/10.30935/ejimed/11260

Turan, Z., \& Akdag-Cimen, B. (2020). Flipped classroom in English language teaching: a systematic review. Computer Assisted Language Learning, 33(5), 590-606. https://doi.org/10.1080/09588221.2019.1584117

Uzunboylu, H., \& Karagozlu, D. (2015). Flipped classroom: A review of recent literature. World Journal on Educational Technology, 7(2), 142-147. https://doi.org/10.18844/wjet.v7i2.46

Yilmaz, R. (2017). Exploring the role of e-learning readiness on student satisfaction and motivation in flipped classroom. Computers in Human Behavior, 70, 251-260. https://doi.org/10.1016/j.chb.2016.12.085

Zainuddin, Z., \& Attaran, M. (2016). Malaysian students' perceptions of flipped classroom: A case study. Innovations in Education and Teaching International, 53(6), 660-670. https://doi.org/10.1080/14703297.2015.1102079

Zhai, X., Gu, J., Liu, H., Liang, J. C., \& Tsai, C. C. (2017). An experiential learning perspective on students' satisfaction model in a flipped classroom context.Journal of Educational Technology \& Society, 20(1), 198-210. https://www.jstor.org/stable/jeductechsoci.20.1.198

Zhang, P., Ma, J., \& Liu, Y. (2014). Flipped classroom: An effective model of improving student teachers' educational technology.Journal of Information Technology and Application in Education,3(3), 144-149. https://doi/10.14355/jitae.2014.0303.02 